\title{
Top topics in HCV research arena
}

\author{
Massimo Puoti, Roberto Rossotti, Giovanna Travi, Maurizio Orso, Maria Cristina Moioli \\ From Second Workshop of the Regional Study Group on HCV in the Calabria Region (Southern Italy). The \\ virus-host-therapy pathway in HCV disease management: from bench to bedside in the era of Directly Act- \\ ing Antivirals \\ Catanzaro, Italy. 16 October 2012
}

\begin{abstract}
A significant improvement in the rate of eradication of Hepatitis C Virus Genotype 1 has been achieved with the addition of Boceprevir and Telaprevir to pegylated interferon and ribavirin. These two drugs are the heralds of a new wave of antivirals that will improve the efficacy of pegylated interferon or even will substitute this drug in interferon free combinations. The results of phase II studies in patients naïve to treatment seem to be very promising strongly supporting the possibility of a large success for a first line all oral antiviral combination in interferon naïve. However, data observed in interferon experienced patients are less exciting and probably more complex treatment regimens will be needed to treat this patients' population.
\end{abstract}

\section{Introduction}

In the last 2 years the development of Directly Acting Antivirals (DAA) for the eradication of Hepatitis C Virus (HCV) infection and the availability of two Protease Inhibitors (PI) -boceprevir and telaprevir- have completely changed the scenario of $\mathrm{HCV}$ research.

Many interesting aspects of $\mathrm{HCV}$ epidemiology and pathogenesis, the relationship among HCV and diabetes or cardiovascular diseases, the improvements in the knowledge of immune response to $\mathrm{HCV}$ and even the research on potentially preventive or therapeutic vaccines have been obscured by the new exciting data on antivirals acting on $\mathrm{HCV}$.

\section{Anti HCV DAA classification}

Actually there are 4 classes of drugs on development with two targets: protease inhibitors, nucleoside/nucleotide polymerase inhibitors and non nucleosides polymerase inhibitors acting on the product of the Non Structural 5b (NS5b) gene of the polymerase (NS5b PolI), inhibitors of the Non Structural 5a (NS5a) gene of the polymerase (NS5aPolI), and cyclophillin inhibitors acting on an host protein that links viral polymerase.

\footnotetext{
* Correspondence: massimopuoti@libero.it
Infectious Diseases Unit AO Ospedale Niguarda Ca' Granda, 20162 Milano,

* Correspondence: massimopuoti@libero.it
Infectious Diseases Unit AO Ospedale Niguarda Ca' Granda, 20162 Milano, Italy
}

\section{Development of anti HCV DAA}

Currently approved are 2 protease inhibitors, telaprevir and boceprevir. In phase 3 trials now are 4 drugs: 2 HCV protease inhibitors TMC435 \& BI1335; nucleotide GS7977; and NS5A BMS052. Phase 3 studies for these drugs should be finished in about one year with varying finish timelines between these drugs.

So in about 1 year we will have 2 brand new classes of drugs BMS052 the potent NS5A polymerase inhibitor, GS7977 the potent nucleotide polymerase inhibitor, plus the 2 new proteases currently in phase 3 BI1335 \& TMC435. At this time we don't know if clinicians will be able to combine the NS5A+GS7977 or a 3-drug combination of a protease TMC435 or BI1335 + the NS5A BMS052+GS7977 [1].

\section{DAA efficacy in phase II studies}

In naïve patients phase II studies with new protease inhibitors or with polymerase inhibitors administered in combination with pegylated interferon + ribavirin showed Sustained Virologic Response (SVR) rates higher than 80\% and in some cases higher than $90 \%$ with shorter treatment duration, less side effects, more convenient schedules in comparison with triple therapy regimen conducted with boceprevir or telaprevir. However the same efficacy was observed with some interferon free combinations of protease inhibitors or polymerase inhibitors with or without 
ribavirin. Results obtained in phase II studies presented at EASL in 2012 [2-14] are summarized in Figure 1.

In patients with $\mathrm{HCV}$ genotype 2 or 3 these results have also been confirmed with nucleotide polymerase inhibitors combined with ribavirin which achieved 100\% SVR rates in small pilot studies [7,14] (Table 1). So it could be supposed that in the future interferon free combination of antivirals with or without ribavirin will be the first line in the treatment of naïve patients with $\mathrm{HCV}$.

In experienced patients with a null or partial response to a previous course of pegylated interferon and ribavirin the results of interferon free combinations are still less impressive; they are good in patients infected with HCV G1b but the rate of SVR in patients with HCV Genotype 1a infection seems to be suboptimal. Results obtained in phase II studies in experience patients with HCV G1 infection presented at EASL are summarized in Figure 2.
Thus three or four antivirals in combination or combinations of antivirals with pegylated interferon will probably be necessary to treat the most difficult to treat patients: those with HCV G1a infection and/or poor response to pegylated interferon and ribavirin and/or with advanced fibrosis.

\section{Safety data with new DAA}

One of the major challenges given by adding telaprevir or boceprevir to pegylated interferon combined with ribavirin is the addition of the toxicities given by these drugs to the engaging series of side effects given by the standard of care. Rash, anemia, neutropenia, thrombocytopenia, dysgeusia, anorectal discomfort have been found more frequently in patients treated with boceprevir and telaprevir. So the lack or the reduction of side effects is a pre requisite for the development of new anti HCV DAA. In fact, most of the new DAA have showed a better tolerability profile in phase II studies that became quite optimal in

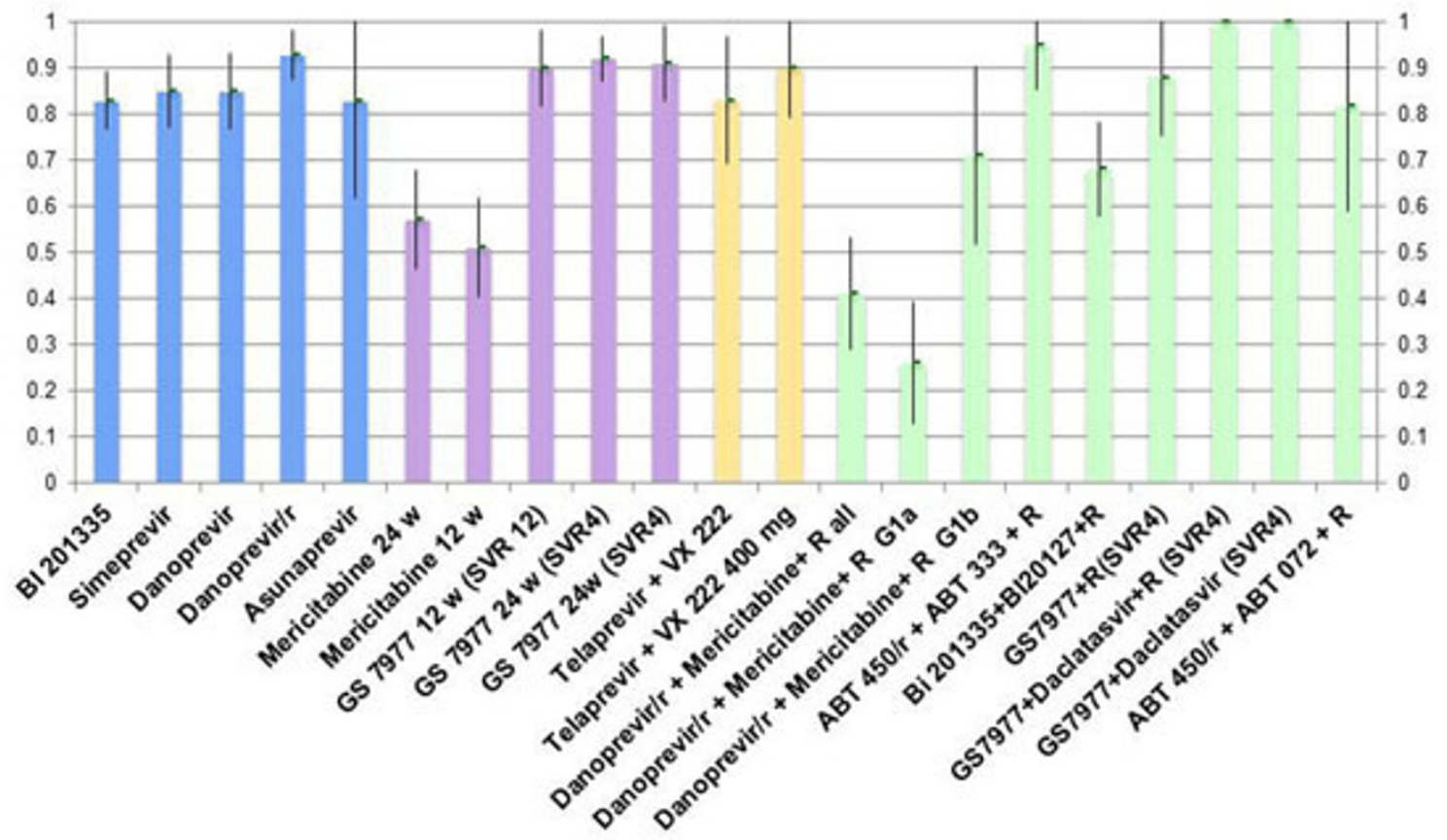

Figure 1 Phase II trials: SVR rate and $\mathbf{9 5 \%} \mathrm{Cl}$ with DAA in HCVG1 naives. Blue, Triple combo with Protease Inhibitors (PI) + Pegylated interferon (P) + Ribavirin ( R ). Purple, Triple combo with NS5aPol inhbitors + PR. Yellow, QUAD two antivirals acting on viral protease and polymerase with pegylated interferon + ribavirin. Green, Interferon free combos. They are NOT HEAD TO HEAD STUDIES. 
Table 1 Phase II trials: SVR Rate with DAA in HCVG 2-3 naives and experienced (NOT HEAD TO HEAD STUDIES)

\begin{tabular}{lllllll}
\hline DAA & Class & DAA Duration & PR Duration & N & SVR 4*/24 Naives & SVR 4 experienced \\
\hline PR+GS-7977 & NS5bPoll & $12 w k$ & $12 w k$ & 11 & $11 / 11$ \\
& & $12 w k$ & $8 w k$ & 10 & $10 / 10$ \\
& & $12 w k$ & $4 w k$ & 9 & $10 / 10$ \\
\hline GS-7977 + R & Ns5bPoll & $12 w k$ & 0 & 11 & $11 / 11$ \\
\hline GS-7977+R & Ns5bPoll & $12 w k$ & 0 & 25 & & $12 / 15$ \\
\hline GS7977 + Daclatasvir $\pm R$ & NNS5bPoll + NS5aPoll $\pm R$ & $24 w k$ & 0 & 30 & $28 / 30^{*}$ \\
& & $24 w k$ & 0 & 14 & $11 / 14^{*}$ \\
\hline
\end{tabular}

Abbreviations: DAA: Directly Acting Antiviral; NS5b Poll : NS5b polymerase inhibitor; NS5a Polymerase Inhibitor; PR Pegylated Interferon combined with Ribavirin; wk: week; SVR: Sustained Virologic Response; SVR 4: HCVRNA below the level of detection with Roche TaqMan assay 4 weeks after treatment withdrawal; SVR 24: HCVRNA below the level of detection with Roche TaqMan assay 24 weeks after treatment withdrawal

interferon free combinations. Sometimes phase II studies are sufficient to reveal important side effects and it is demonstrated by the fact that the development of several antivirals has been stopped because of occurrence of severe side effects in few patients. Nevertheless there is a strong need for large sample size in order to really assess the safety profile of these drugs. Some safety signals observed in dose finding studies with new drugs (i.e., rash with BI 201335, hypertransaminasemia with unboosted danoprevir) suggest the need for a careful evaluation of side effects in phase III studies. Other side effects such as gastrointestinal symptoms or jaundice due to Gilbert-like hyperbilirubinemia are less important for motivated patients enrolled in clinical phase II trials, but could reduce the acceptability of and adherence to treatment in the real life setting.

\section{Caveats in the results of phase II studies on anti HCV DAA}

Even if the results of these studies are exciting there are some caveats that should be taken into account:
- Patients with HCV infection even if stratified according to genotype are very heterogeneous;

- In most of the studies and especially with interferonfree combinations the sample size was extremely small, so they should be regarded as proof of concept studies rather than dose finding studies, as are most of the traditional phase II studies;

- The duration of antiviral therapy in most studies was 12 weeks: obtaining an eradication of HCV with only three months of treatment is exciting but is not the Holy Grail and longer treatment duration could also be acceptable in the most difficult to treat patients. So data with longer treatment duration are still needed in harder to treat population;

- In some studies a negative HCV RNA 4 weeks after stopping treatment was assumed as a proof of $\mathrm{HCV}$ eradication, but probably we still have to identify the optimal follow up duration needed to define SVR to Interferonfree regimens;

- Adherence and resistance are crucial for interferonfree combinations and when prescribing them first-line

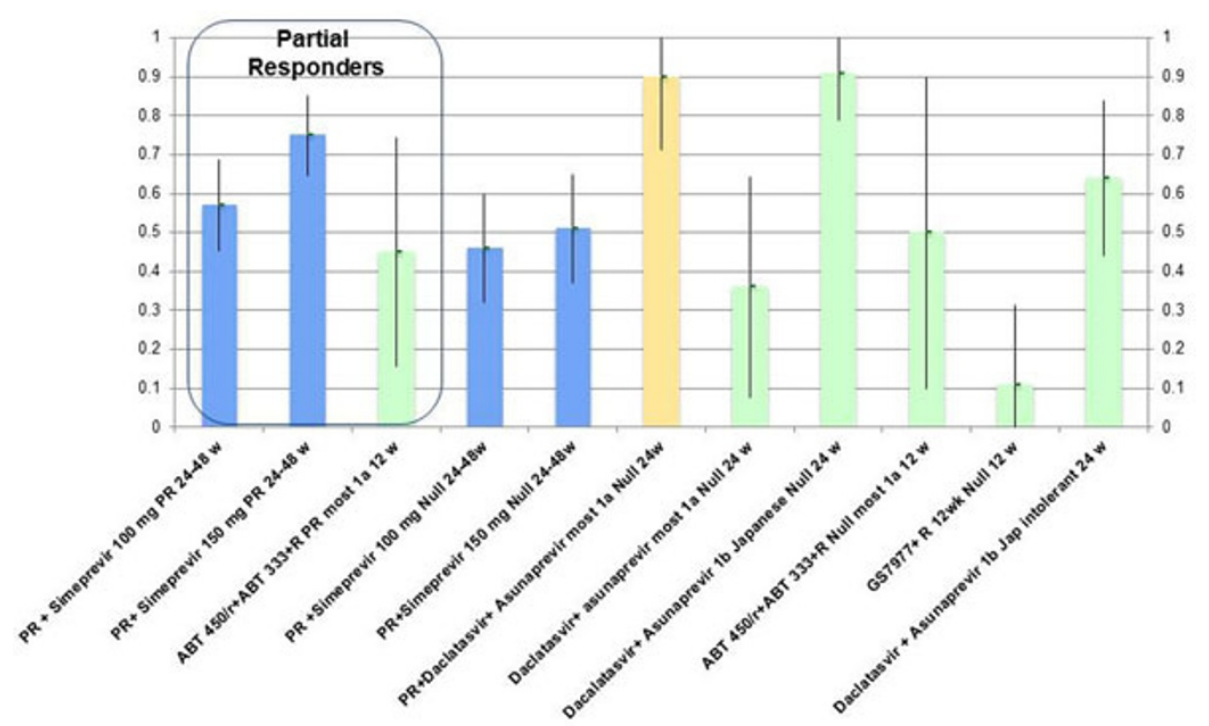

Figure 2 Phase II trials: SVR rate with DAA in HCVG1 non responders. Blue, Triple combo with PI + PR. Yellow, QUAD with P+R. Green, interferon free combos. 
treatments, a second line rescue line without cross-resistance to the drugs previously administrated should be identified.

\section{Conclusions}

In summary, exciting new times are coming for $\mathrm{HCV}$ treating physicians and persons living with $\mathrm{HCV}$. However we have to be prepared to face an insidious and able enemy who should probably be eradicated only combining prudence and knowledge of its heterogeneous nature.

\section{List of abbreviations used}

DAA: Directly Acting Antivirals; HCV: Hepatitis C Virus; PI: Protease Inhibitors; SVR: Sustained Virologic Response; PI: Protease Inhibitor; NS5b Poll: NS5b polymerase inhibitor; NS5a Poll: Polymerase Inhibitor; PR: Pegylated Interferon combined with Ribavirin; wk: week; SVR 4: HCVRNA below the level of detection with Roche TaqMan assay 4 weeks after treatment withdrawal; SVR 24: HCVRNA below the level of detection with Roche TaqMan assay 24 weeks after treatment withdrawal.

\section{Declarations}

Publication of this supplement was partly supported by an unrestricted grant provided by Roche. The articles were independently prepared by the authors with no input from Roche. Roche were not involved in selecting the articles for the supplement. The pegylated interferon treatment mentioned in this article is produced by Roche.

\section{Acknowledgements}

This article has been published as part of BMC Infectious Diseases Volume 12 Supplement 2, 2012: Proceedings of the Second Workshop of the Regional Study Group on HCV in the Calabria Region (Southern Italy). The virus-hosttherapy pathway in HCV disease management: from bench to bedside in the era of Directly Acting Antivirals. The full contents of the supplement are available online at http://www.biomedcentral.com/bmcinfectdis/ supplements/12/S2.

\section{Competing interests}

Massimo Puoti has received fees as a member of occasional Advisory Boards, and/or speaker in own events and/or teacher in courses for employees and/or research grants and/or is involved as principal investigator in trials supported from the following drug companies: Abbott, BMS, Boheringer Ingelheim, Gilead Sciences, Janssen, MSD, Roche, Vertex. Roberto Rossotti, Giovanna Travi, Maurizio Orso, and Maria Cristina Moioli have been involved as coinvestigators in trials supported by Abbott, BMS, Boheringer Ingelheim, Gilead Sciences, Janssen, Roche.

Published: 12 November 2012

\section{References}

1. Levine J: HCV Update Selected Highlights: key new HCV drugs, timelines \& recent news developments.[http://www.natap.org].

2. Zeuzem S, Berg T, Gane E, Ferenci P, Foster GR, Fried MW, Hezode C, Hirschfield G, Jacobson I, Nikitin I, Pockros P, Poordad F, Lenz O, Peeters M, Sekar V, De Smedt G, Beumont-Mauviel M: TMC435 in HCV genotype 1 patients who have failed previous pegylated interferon/ribavirin treatment: final SVR24 results of the ASPIRE trial. 47th Annual Meeting of the European Association for the Study of the Liver, April 18-22, 2012, Barcelona, Spain , abstract 2.

3. Kowdley KV, Lawitz E, Crespo I, Hassanein T, Davis M, DeMicco M, Nelson DR, Bernstein D, Afdhal NH, Jacobson I, Vierling J, Gordon S, Anderson JK, Hyland RH, Hindes RG, Baker C, Sorensen R, Albanis E, Symonds WT, Berrey MM, ATOMIC Investigators: ATOMIC: 97\% RVR for PSI7977 + PEG/RBV X 12 week regimen in HCV GT1: An end to response- guided therapy? 47th Annual Meeting of the European Association for the Study of the Liver, April 18-22, 2012, Barcelona, Spain, abstract 1.

4. Poordad F, Lawitz E, DeJesus E, Kowdley KV, Gaultier I, Cohen DE, Xie W, Larsen L, Pilot-Matias T, Koev G, Dumas E, Podsadecki T, Bernstein B: ABT072 or ABT-333 combined with pegylated interferon/ribavirin after 3-day monotherapy in HCV genotype 1 (GT1)-infected treatment-naïve subjects: 12-week sustained virologic response (SVR12) and safety results. 47th Annual Meeting of the European Association for the Study of the Liver, April 18-22, 2012, Barcelona, Spain , abstract 1206.

5. Zeuzem S, Soriano V, Asselah T, Bronowicki JP, Lohse A, Mullhaupt B, Schuchmann M, Bourliere M, Buti M, Roberts S, Gane E, Stern JO, Kukolj G, Dai L, Böcher WO, Mensa FJ: SVR4 and SVR12 with an interferon-free regimen of $\mathrm{BI} 201335$ and $\mathrm{BI} 207127,+/$ - ribavirin, in treatment-naïve patients with genotype-1 HCV infection: interim results of SOUND-C2. 47th Annual Meeting of the European Association for the Study of the Liver, April 18-22, 2012, Barcelona, Spain , abstract 101.

6. Gane EJ, Stedman CA, Hyland RH, Sorensen RD, Symonds WT, Hindes RG, Berrey MM: ELECTRON: once daily PSI-7977 plus RBV in HCV GT1/2/3. 47th Annual Meeting of the European Association for the Study of the Liver, April 18-22, 2012, Barcelona, Spain , abstract 1113.

7. Gane EJ, Stedman C, Anderson J, Hyland R, Hindes R, Symonds W Berrey MM: $100 \%$ rapid virologic Response for PSI-7977 + ribavirin in genotype 1 Null responders (ELECTRON): early viral decline similar to that observed in genotype 1 and genotype 2/3 treatment-naïve patients. 19th Conference on Retroviruses and Opportunistic Infections, March 5-8, 2012, abstract 54LB.

8. Gane EJ, Stedman CA, Hyland RH, et al: Once Daily PSI-7977 plus RBV: pegylated interferon-alfa not required for complete rapid viral response in treatment-naive patients with HCV GT2 or GT3. 62nd Annual Meeting of the American Association for the Study of Liver Disease (AASLD 2011). San Francisco, November 4-8. 2011 , Abstract 34.

9. Poordad F, Lawitz E, Kowdley KV, Everson GT, Freilich B, Cohen D, Siggelkow S, Heckaman M, Menon R, Pilot-Matias T, Podsadecki T, Bernstein B: 12-week interferon-free regimen of ABT-450/r+ABT-333+ ribavirin achieved SVR12 in more than $90 \%$ of treatment-naïve HCV genotype-1-infected subjects and $47 \%$ of previous non-responders. 47 th Annual Meeting of the European Association for the Study of the Liver, April 18-22, 2012, Barcelona, Spain, LB abstract 1399.

10. Lawitz E, Poordad F, Kowdley KV, Jensen D, Cohen DE, Siggelkow S, Wikstrom K, Larsen L, Menon RM, Podsadecki T, Bernstein B: A 12-week interferon-free regimen of ABT-450/r, ABT-072, and Ribavirin was well tolerated and achieved sustained virologic response in $91 \%$ treatmentnaïve HCV IL28B-CC genotype-1-infected subject. 47th Annual Meeting of the European Association for the Study of the Liver, April 18-22, 2012, Barcelona, Spain, LB abstract 13.

11. Chayama K, Takahashi S, Kawakami Y, et al: Dual oral combination therapy with the NS5A inhibitor BMS-790052 and the NS3 protease inhibitor BMS-650032 achieved 90\% sustained virologic response (SVR12) in HCV genotype $1 \mathrm{~b}$-infected null responders. 62nd Annual Meeting of the American Association for the Study of Liver Diseases. San Francisco, November 4-8. 2011 , Abstract LB-4.

12. Suzuki F, Ikeda K, Toyota J, Karino Y, Ohmura T, Chayama K, Takahashi S, Kawakami Y, Ishikawa H, Watanabe H, Hu W, McPhee F, Hughes $E_{\text {, }}$ Kumada H: Dual oral therapy with the NS5A inhibitor dclatasvir (BMS790052) and NS3 protease inhibitor asunaprevir (BMS-650032) in HCV genotype $1 \mathrm{~b}$-infected null responders or ineligible/intolerant to PEGIFN. 47th Annual Meeting of the European Association for the Study of the Liver, April 18-22, 2012, Barcelona, Spain, LB abstract.

13. Sulkowski M, Rodriguez-Torres M, Lawitz E, Shiffman M, Pol S, Herring R, McHutchison J, Pang P, Brainard D, Wyles D, Habersetzer F: High sustained virologic response rate in treatment-naïve HCV genotype $1 \mathrm{a}$ and $1 \mathrm{~b}$ patients treated for 12 weeks with an interferon-free all-oral quad regimen: interim results. 47th Annual Meeting of the European Association for the Study of the Liver, April 18-22, 2012, Barcelona, Spain, LB abstract 1421.

14. Sulkowski M, Gardiner D, Lawitz E, Hinestrosa F, Nelson D, Thuluvath $P$, Rodriguez-Torres M, Lok A, Schwartz H, Reddy KR, Eley T, Wind-Rotolo M, Huang SP, Gao M, McPhee F, Hindes R, Symonds B, Pasquinelli C, Grasela D, Al444040 Study Group: Potent viral suppression with all-oral combination of daclatasvir (NS5A inhibitor) and GS-7977 (NS5B inhibitor), +/-ribavirin, 
in treatment-naïve patients with chronic HCV GT1, 2, or 3. 47th Annual Meeting of the European Association for the Study of the Liver, April 18-22, 2012, Barcelona, Spain , LB abstract 1422.

doi:10.1186/1471-2334-12-S2-S7

Cite this article as: Puoti et al:: Top topics in HCV research arena. BMC Infectious Diseases 2012 12(Suppl 2):S7.

Submit your next manuscript to BioMed Central and take full advantage of:

- Convenient online submission

- Thorough peer review

- No space constraints or color figure charges

- Immediate publication on acceptance

- Inclusion in PubMed, CAS, Scopus and Google Scholar

- Research which is freely available for redistribution

Submit your manuscript at www.biomedcentral.com/submit 